\title{
Immunohistochemical characterization of the rabbit tracheal cartilages
}

\author{
Richard D. Wemer ${ }^{1}$, Michael Detamore ${ }^{2}$, Robert A. Weatherly ${ }^{3}$ \\ ${ }^{1}$ Department of Otolaryngology-Head and Neck Surgery, Park Nicollet Clinics, St. Louis Park, USA \\ ${ }^{2}$ Department of Chemical and Petroleum Engineering, University of Kansas, Kansas City, USA \\ ${ }^{3}$ Department of Otolaryngology-Head and Neck Surgery, University of Kansas, Kansas City, USA \\ Email: wemerr@parknicollet.com; detamore@ku.edu; rweatherly@kumc.edu
}

Received 5 August 2010; revised 18 August 2010; accepted 27 August 2010.

\section{ABSTRACT}

The objective of this study was to immunohistochemically elucidate the major extracellular matrix constituents of rabbit tracheal cartilage. The impetus for this project is the need for crucial design and validation criteria for tissue engineering juxtaposed with the conspicuous lack of trachea extracellular matrix data in the literature. Tracheal tissue specimens were harvested from New Zealand White rabbits, and were immunostained for collagen I, collagen II, aggrecan and decorin; and a Verhoeff-Van Gieson stain was performed to visualize elastin. The most striking result was the highly organized relationship between distinct fibrous (containing collagen I, decorin and elastin) and hyaline-like (containing collagen II and aggrecan) regions of the tracheal wall. The tracheal cartilage stained strongly with collagen II throughout, with periodic bands of aggrecan in the tracheal arches, meaning that there were areas void of aggrecan immunostaining alternating with areas with strong aggrecan immunostaining. In contrast, the periphery of the cartilage and the perichondrium itself exhibited strong collagen I staining and no collagen II staining. Elastin fibers and decorin were also detected along the periphery of the cartilage in the perichondrium and corresponded highly with the distribution of collagen I staining. The body of the rabbit trachea is therefore composed of a hyaline-cartilage structure primarily made of collagen II and bands of aggrecan, surrounded by a fibrous region composed of elastin and collagen $I$, indicative of a flexible tissue with distinct regions of compressive integrity. This information will be a valuable reference to future tissue engineering efforts in the creation of a biosynthetic substitute for laryngotracheal reconstruction.
Keywords: Trachea; Collagen; Aggrecan; Decorin; Elastin.

\section{INTRODUCTION}

The treatment of subglottic stenosis is a difficult clinical problem that may require invasive measures at both primary and donor sites. After failure of more conservative measures, open airway surgery is often performed, which requires donor cartilage tissue to be harvested, usually a segment of autologous costal cartilage. Such procedures are complicated by long healing times, donor site complications including pain and pneumothorax, size and shape mismatches, and prolonged hospital stays.

Tissue-engineered cartilage offers a viable alternative to these highly morbid procedures. Donor site complications could be eliminated, and tissue could be shaped appropriately for specific defects in the tracheal wall. Tissue engineering attempts for the trachea are still preliminary, from a clinical perspective, at this time. Nevertheless, tracheal tissue engineering is a burgeoning field [1-13], and the level of urgency is high for providing crucial characterization data for tissue engineers, both to develop new ideas for design strategies for recapitulating the native tracheal structure, and to elucidate validation criteria.

We have used rabbits in previous tracheal defect reconstruction studies [14-16], as rabbits are an ideal animal model for early-stage in vivo investigations. A review of animal models for trachea research suggested that large animals such as goats and sheep should be used for tracheal tissue engineering based on size and cell number [17]. However, the rabbit has heretofore been a more commonly used animal model for tracheal tissue engineering and is a logical stepping stone en route to larger animal models. For this reason, we have selected the rabbit for our immunohistochemical charac- 
terization of the trachea.

In contrast to the trachea, the extracellular matrix of the vocal folds of the larynx (which lie just superior to the trachea) continues to be a popular research topic, including studies of collagen types, elastin, and proteoglycans [18-36]. However, despite the wide variety of trachea characterization efforts, ranging from camel trachea dimensions [37] to dolphin trachea biomechanics [38], and even speculation of airflow in dinosaur tracheas [39], very little is known about the distribution of key extracellular matrix components of the trachea.

Evans and colleagues presented a nice series of matrix studies on the basement membrane zone associated with the trachea in monkeys and rats [40-42]. However, only a handful of studies have begun to elucidate the collagen and/or elastin content of the trachea in guinea pigs, mice and rats [43-47], in pigs [48, 49], and in humans [50, 51]. It is known that collagen fibers in the trachea run obliquely and are intermingled $[43,51,52]$, that collagen I appears predominately in the perichondrium and collagen II appears predominately in the cartilaginous tracheal body [45-47,50]. It is also known that elastic fibers may be abundant in the perichondrium of the trachea $[36,43,44]$, forming an extensive network that extends into the posterior membranous tracheal wall [36]. With regard to elastin, it is noteworthy that a pair of studies found trappin-2 (also known as elafin), an elastase inhibitor, in the trachea $[48,49]$.

In addition, specific glycosaminoglycans (GAGs) were identified immunohistochemically in rat tracheas, although the heterogeneous distributions of chondroitin-4-sulfate and chondroitin-6-sulfate were not in agreement [47]. Toluidine blue $\mathrm{O}$ staining in humans also revealed a heterogeneous GAG distribution [51], although the distributions of specific proteoglycans was not identified. It is also known that regions of the trachea are calcified, although there is a debate as to whether the tissue is commonly ossified [46,47,50,53].

What was not known prior to the current study was the distribution of key proteoglycans, which have important functional roles, and whether their distribution coincided with the distribution of collagen types I and II. Moreover, it was unknown whether the distribution of collagens I and II observed in the trachea of rats [45-47] and humans [50] would be observed in the rabbit trachea as well. Therefore, the objective of the current study was to identify the distributions of elastin, collagen I, and collagen II; as well as two key proteoglycans (aggrecan and decorin) in the rabbit trachea. These matrix components were chosen based on their relevance to tissue engineering, implications for mechanical performance, and to establish relative distribution and abundance for validation of engineered constructs. Given that collagen II and aggrecan are associated with hyaline cartilage, whereas elastin, collagen I and decorin are associated primarily with fibrous tissues [54], we hypothesized that aggrecan would coincide with collagen II distribution, and that decorin would coincide with collagen I and elastin distribution. The relative distributions of these key extracellular matrix components will be crucial to tissue engineering efforts that address surgical repair of laryngotracheal stenosis.

\section{METHODS}

\subsection{Specimen Preparation}

Four New Zealand White rabbits were obtained and sacrificed at adult age. All rabbits were male and weighed approximately $9 \mathrm{lbs}$. They were sacrificed after undergoing a single cardiovascular physiology experiment not relevant to tracheal protein structure or synthesis. Immediately after sacrifice, the larynx-trachea complexes were collected and stored in PBS-saturated gauze at $-20^{\circ} \mathrm{C}$ prior to sectioning. Serial $10 \mu \mathrm{m}$ frozen sections were taken from each of the samples. Sections were mounted on slides, fixed in chilled acetone for $20 \mathrm{~min}$, and then stored at $-20^{\circ} \mathrm{C}$ until further use.

\subsection{Verhoeff-Van Gieson Elastic Tissue Stain}

Fixed rabbit tissue samples were stained for elastin. The samples were first placed in an iron hematoxylin solution for $10 \mathrm{~min}$ and then rinsed in distilled water and differentiated in $2 \%$ ferric chloride. After rinsing in distilled water and placing in 95\% alcohol, the samples were counterstained with Van Gieson's solution (Sigma Aldrich; St. Louis, MO) for $4 \mathrm{~min}$. The samples were then dehydrated in graded alcohol and then cleared in xylene and mounted.

\subsection{Immunohistochemistry}

Slides were placed in a Biogenex i6000 (San Ramon, CA) autostainer and rehydrated for $5 \mathrm{~min}$ in PBS. Endogenous peroxidase activity was quenched with $1 \%$ hydrogen peroxide in methanol for $30 \mathrm{~min}$. Specimens were blocked with serum from the secondary antibody host for $20 \mathrm{~min}$ and followed by incubation with the primary antibody for $60 \mathrm{~min}$ (dilutions provided in Table 1). Mouse monoclonal IgG anti-collagen I and mouse monoclonal IgG anti-collagen II antibodies were obtained from Accurate Chemical and Scientific (Westbury, NY) and Chondrex, LLC (Redmond, WA), respectively. Mouse monoclonal IgG anti-aggrecan and sheep polyclonal IgG anti-decorin were obtained from Abcam (Cambridge, MA). Negative controls were assessed by omission of the primary antibody, and the absence of non-specific staining was verified.

The specimens were then incubated with the appro- 
Table 1. Immunohistochemistry primary antibody dilutions.

\begin{tabular}{ll}
\hline ECM Constituent & Primary Antibody Dilution \\
\hline Collagen I & 1,500 \\
Collagen II & 1,000 \\
Decorin & 100 \\
Aggrecan & 50 \\
\hline
\end{tabular}

priate secondary antibody for $30 \min (1: 300$ dilution), followed by an avidin-biotinylated enzyme complex for $30 \mathrm{~min}$ and then 3,3'-diaminobenzidine for $4 \mathrm{~min}$. Avidin-biotin complex kits were obtained from Vector Laboratories (Burlingame, CA). The kits consisted of a biotinylated secondary antibody (horse anti-mouse IgG, or rabbit anti-sheep IgG), the corresponding host animal serum, and an avidin-biotinylated enzyme complex. Slides were removed from the autostainer, counterstained with hematoxylin, dehydrated in graded ethanol and mounted.

\section{RESULTS}

\subsection{Collagen II and Aggrecan}

The tracheal hyaline cartilage stained strongly with collagen II throughout the body of the cartilage ring. Outside of the cartilage ring, no collagen II staining was detected Figure 1(a). Also, within the tracheal body, we did observe staining for aggrecan. Aggrecan, however, had a different staining pattern within the tracheal body. The body of the cartilage exhibited a striped effect where there were areas void of aggrecan immunostaining, alternating with areas displaying strong aggrecan immunostaining. This was observed throughout all sections of the tracheal cartilage, on multiple slides, and from all observed animal specimens. There was also some aggrecan staining in the surrounding tissues outside of the cartilage ring Figure 1(b).

\subsection{Collagen I, Decorin, and Elastin}

Collagen I immunostaining was observed around the periphery of the tracheal body cartilage. There was no immunostaining in the cartilage body itself Figure 2(a). Decorin staining was also identified in the tracheal cartilage samples. Decorin was seen in the periphery of the cartilage and perichondrium, as well as the surrounding soft tissues. This distribution was very similar to the distribution seen with collagen I staining Figure 2(b), with no decorin staining being observed in the hyaline cartilage itself.

Elastin fibers, detected with the Verhoeff-Van Gieson stain, were also located along the periphery of the cartilage within the perichondrium. No staining was seen in the pericellular areas or in within the cartilage extracellular matrix. Elastin staining corresponded highly with the distribution of collagen I and decorin staining Figure 2(c).

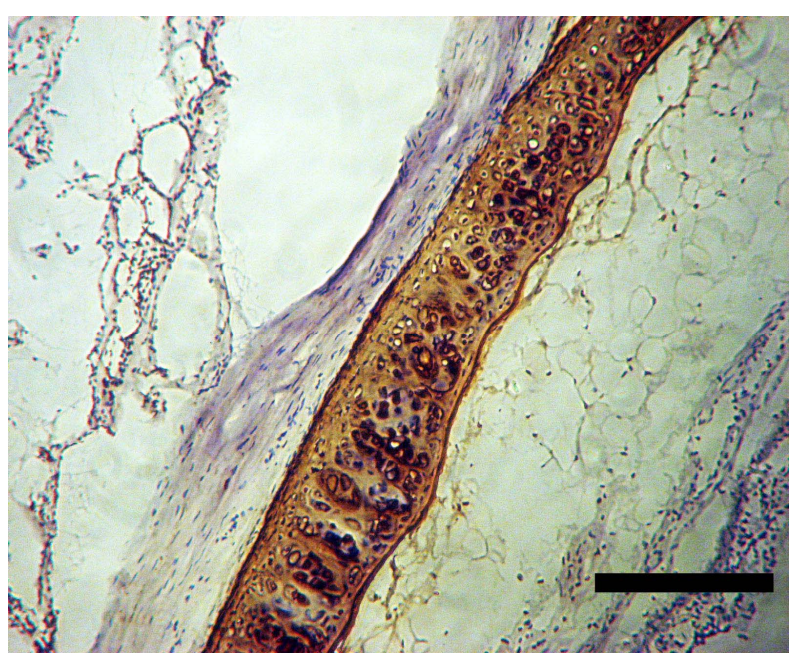

(a)

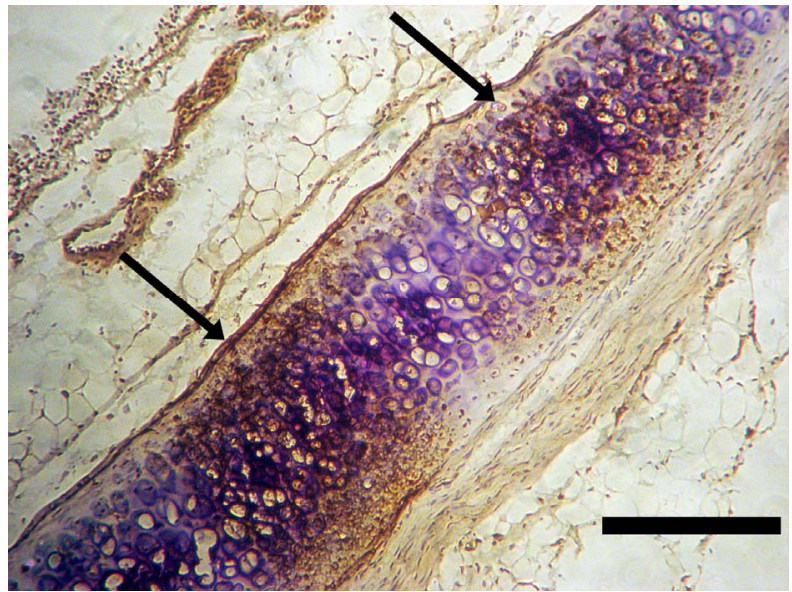

(b)

Figure 1. Collagen II and Aggrecan Localization. Tracheal cartilage with collagen II (brown immunostain) demonstrated throughout the tracheal arch (a). A striped effect (arrows) was observed in the tracheal arch with aggrecan immunostaining (b). Hematoxylin counterstain. Scale bars are $50 \mu \mathrm{m}$ (a) and $100 \mu \mathrm{m}$ (b).

\section{COMMENTS}

To the best of our knowledge, the current study is the first to describe the extracellular matrix of the rabbit trachea, and more importantly, the first to investigate the distribution of key proteoglycans in the trachea and correlate their distribution with collagens I and II. The current study was in agreement with previous findings in other species that found collagens I and II in mutually exclusive regions [45-47,50], with the former present in only the surrounding perichondrium and the latter present in only the body of the tracheal cartilage. Furthermore, the current study was in agreement with a previ- 


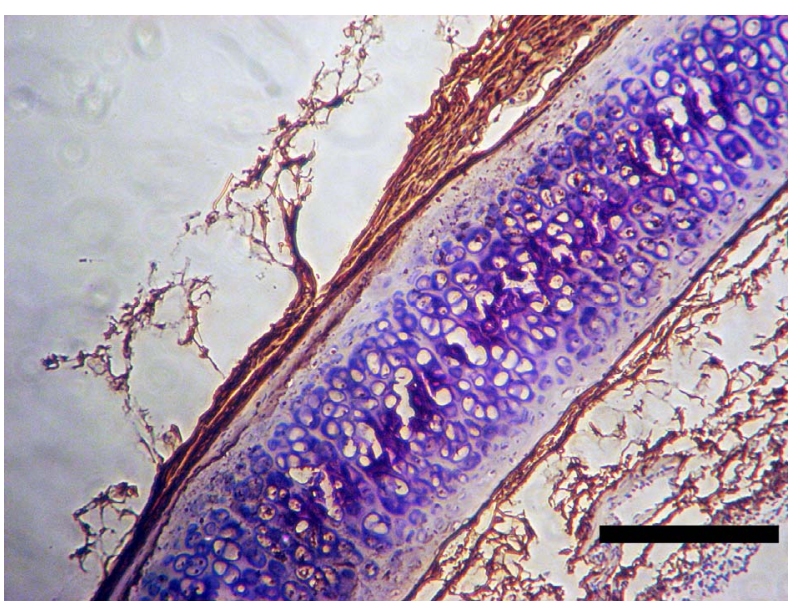

(a)

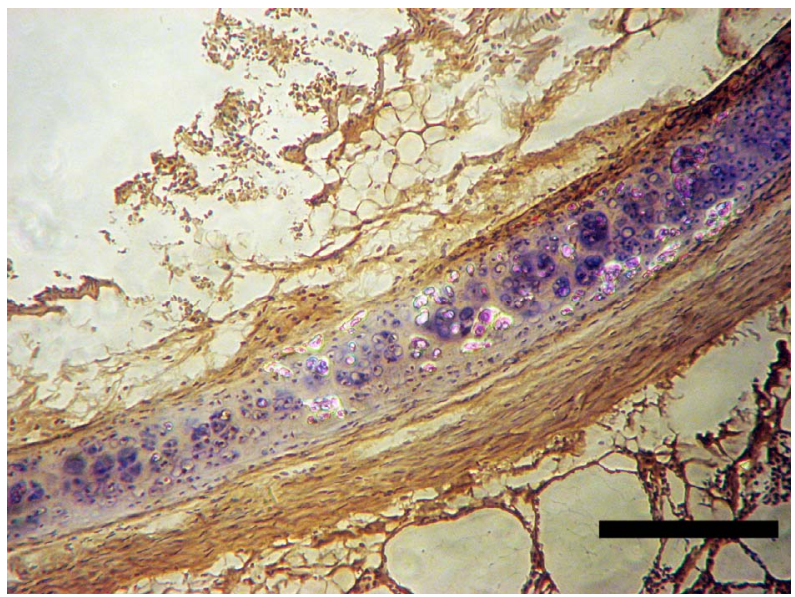

(b)

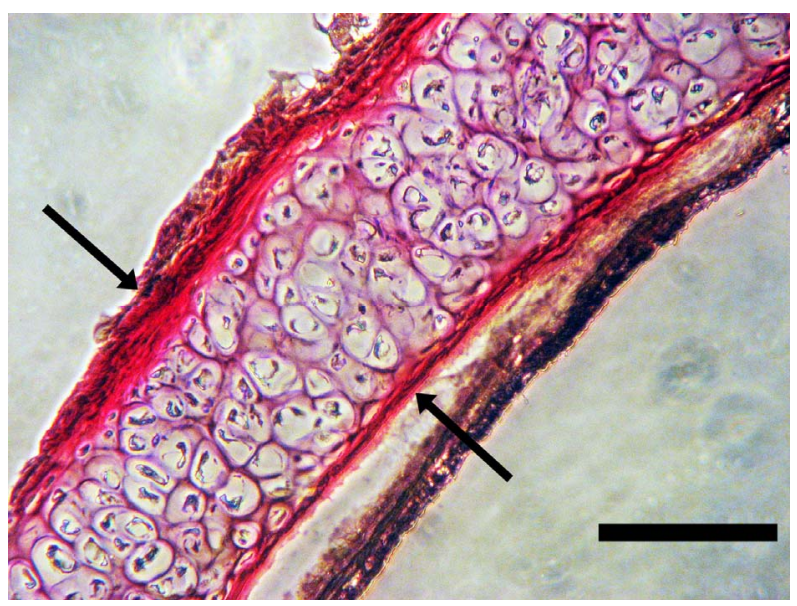

(c)

Figure 2. Collagen I, Decorin and Elastin Localization. Collagen I was peripheral to the tracheal arch (a). Decorin was also peripheral to the tracheal arch (b). Verhoeff-Van Gieson stain for elastin (black bands marked by arrows) (c). Counterstain for (a) and (b) was hematoxylin. Scale bars are $100 \mu \mathrm{m}(\mathrm{a}, \mathrm{c})$ and $50 \mu \mathrm{m}(\mathrm{b})$. ous study in guinea pigs that found elastin in the tracheal periphery [43].

Although the distributions of three specific GAGs (most likely chondroitin-4-sulfate, chondroitin-6 sulfate and keratan sulfate) were elucidated in rats [47], the relevant and functionally more significant distribution of proteoglycans in the trachea was heretofore unknown. As hypothesized, aggrecan and collagen II distribution coincided, and decorin distribution was consistent with collagen I and elastin. However, an interesting and unexpected finding was the observation of a striped or "layered" effect with regard to the staining pattern of aggrecan (Figure 3). This observation is the first of its kind and its significance is not yet clear. Nevertheless, it is likely that this pattern of aggrecan distribution may have an important functional role. For example, periodic regions of increased compressive integrity, interspersed with regions of more flexibility, may provide the tracheal cartilaginous arch with a balance of flexibility and rigidity. The need for aggrecan to promote such a balance in a tissue engineered construct is a hypothesis worth exploring in the future.

Both collagen I and elastin were found to stain around the periphery of the tracheal body. Decorin, which has been described to "decorate" collagen, was also found in the extracellular matrix surrounding the tracheal body. Previous studies have demonstrated a decorin-collagen interaction, concluding that decorin plays a role in regulating collagen fiber formation [55]. One study demonstrated a decrease in collagen fiber diameter, as well as altered collagen morphology in decorin-deficient mice [56]. It may, therefore, be possible that the close alliance of decorin and collagen I are necessary for structural integrity of the tracheal arches, while the relationship of aggrecan and collagen II are primarily responsible for optimal flexibility of the tracheal cartilages.

\section{Aggrecan Staining: Tracheal Cartilage}

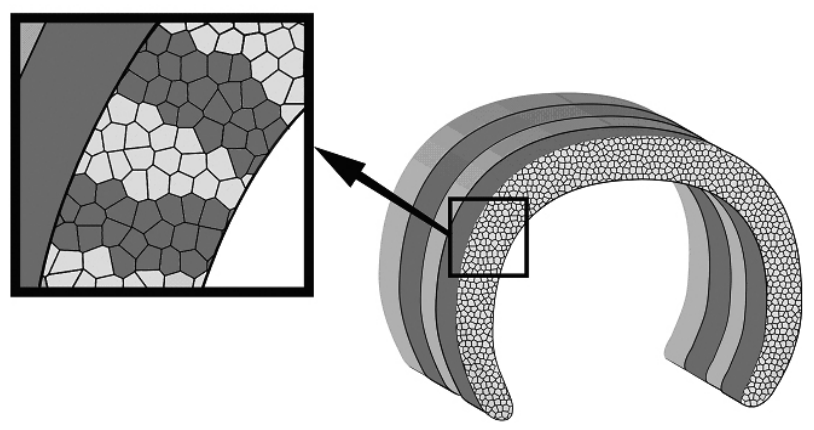

Figure 3. Schematic of Aggrecan Staining in Tracheal Cartilage. Aggrecan was located in such a way as to demonstrate a "layered" or "striped" appearance within the body of the tracheal cartilagenous arch. See also Figure 1(b). 
The biochemical characterization of the rabbit trachea is an important step for a tissue engineering solution to the treatment of airway stenosis. This animal model has been employed for reasons presented earlier, as well as for the rabbit laryngotracheal segment's size closely approximating that of a young pediatric population, of high relevance to tissue engineering for use in treating human disease. In demonstrating the composition of a portion of the laryngotracheal complex, we can then attempt to engineer a tissue that possesses properties similar to that of the native tissue. Future studies will be required to elucidate whether any part of the tracheal body possesses an osseous character (e.g., alkaline phosphatase activity and collagen $\mathrm{I}$ in addition to calcium) $[46,47,50,53]$. Moreover, other trachea characterization efforts will be crucial for construct design and analysis, in particular, studies of the biomechanics of the trachea [51,57-59], the fluid dynamics of air flow through the trachea [60-65], and characterization of surrounding tissues such as the tracheal smooth muscle.

The identification of native tracheal proteins and proteoglycans is critical to the actual construction of tissue-engineered implants. The identification of proteins such as collagen I and II, as well as proteoglycans like decorin and aggrecan, may ultimately lend information as to what substrates are required to produce a suitable cartilage graft. We must, however, remain cautious when considering the need to replicate native tracheal cartilage. The biochemical composition of cartilage is complex, and an exact reproduction of the structure may be neither feasible nor warranted to successfully reconstruct the trachea after injury to a tracheal segment. For example, a newly formed cartilage segment may merely need to possess rigidity, but not maximal flexibility, depending on the size and length of the diseased tracheal segment to be replaced. Additional aspects of tracheal reconstruction such as mucosal resurfacing and vascular supply to large segments, as highlighted by the Leuven Tracheal Transplant Group from Belgium [66], will also need to be addressed as the process of engineered cartilage replacement for tracheal defects becomes more clearly defined.

In the current study, we have demonstrated that the body of the tracheal ring is composed of collagen II and bands of aggrecan (hyaline-like tissue), surrounded by a supporting matrix composed of collagen I, elastin, and decorin (fibrous-like tissue). Looking forward, the information obtained in the current study can be applied to the construction of a bioengineered tracheal graft. In an endeavor to replicate the tracheal cartilage ultrastructure, an ideal graft would possess enough rigidity to withstand stresses, but remain flexible enough to allow for motion and other functional measures. Future studies as described above will be required to correlate the structure of the tracheal cartilage to its function (fluid mechanics of airflow and biomechanical integrity).

\section{ACKNOWLEDGEMENTS}

All of the authors in this study had full access to all the data in the study and take responsibility for the integrity of the data and the accuracy of the data analysis.

\section{REFERENCES}

[1] Tan, Q., Steiner, R., Hoerstrup, S.P and Weder, W. (2006) Tissue-engineered trachea: History, problems and the future. European Journal of Cardio-Thoracic Surgery, 30 (5), 782-786.

[2] Kojima, K. and Vacanti, C.A. (2004) Generation of a tissue-engineered tracheal equivalent. Biotechnology and Applied Biochemistry, 39(Pt 3), 257-262.

[3] Bucheler, M. and Haisch, A. (2003) Tissue engineering in otorhinolaryngology. DNA Cell Biology, 22(9), 549-564.

[4] Grillo, H.C. (2002) Tracheal replacement: A critical review. The Annals of Thoracic Surgery, 73(6), 1995-2004.

[5] Grillo, H.C. (2003) Tracheal replacement. The Journal of Thoracic and Cardiovascular Surgery, 125(4), 975.

[6] Grillo, H.C. (2005) Bioengineered airway tissue. The Journal of Thoracic and Cardiovascular Surgery, 129(5), 1208.

[7] Birchall, M. and Macchiarini, P. (2008) Airway transplantation: A debate worth having? Transplantation, 85 (8), 1075-1080.

[8] Doss, A.E., Dunn, S.S., Kucera, K.A., Clemson, L.A. and Zwischenberger, J.B. (2007) Tracheal replacements: Part 2. ASAIO Journal, 53(2), 631-639.

[9] Kucera, K.A., Doss, A.E., Dunn, S.S., Clemson L.A. and Zwischenberger J.B. (2007) Tracheal replacements: Part 1. ASAIO Journal, 53(4), 497-505.

[10] Macchiarini, P., Jungebluth, P., Go, T., Asnaghi, M.A., Rees, L.E., Cogan, T.A., Dodson, A., Martorell, J., Bellini, S., Parnigotto, P.P., Dickinson, S.C., Hollander, A.P., Mantero, S., Conconi, M.T. and Birchall, M.A. (2008) Clinical transplantation of a tissue-engineered airway. Lancet, 372(9655), 2023-2030.

[11] Steger, V., Hampel, M., Trick, I., Muller, M. and Walles, T. (2008) Clinical tracheal replacement: Transplantation, bioprostheses and artificial grafts. Expert Review of Medical Devices, 5(5), 605-612.

[12] Asnaghi, M.A., Jungebluth, P., Raimondi, M.T., Dickinson, S.C., Rees, L.E., Go, T., Cogan, T.A., Dodson, A., Parnigotto, P.P., Hollander, A.P., Birchall, M.A., Conconi, M.T., Macchiarini, P. and Mantero, S. (2009) A double-chamber rotating bioreactor for the development of tissue-engineered hollow organs: From concept to clinical trial. Biomaterials, 30(29), 5260-5269.

[13] Jungebluth, P., Go, T., Asnaghi, A., Bellini, S., Martorell, J., Calore, C., Urbani, L., Ostertag, H., Mantero, S., Conconi, M.T. and Macchiarini, P. (2009) Structural and morphologic evaluation of a novel detergent-enzymatic tissue-engineered tracheal tubular matrix. The Journal of Thoracic and Cardiovascular Surgery, 138(3), 586-593.

[14] Grimmer, J.F., Gunnlaugsson, C.B., Alsberg, E., Murphy, H.S., Kong, H.J., Mooney, D.J. and Weatherly, R.A. 
(2004) Tracheal reconstruction using tissue-engineered cartilage. Archives of Otolaryngology-Head \& Neck Surgery, 130(10), 1191-1196.

[15] Robey, T.C., Eiselt, P.M., Murphy, H.S., Mooney, D.J. and Weatherly, R.A. (2000) Biodegradable external tracheal stents and their use in a rabbit tracheal reconstruction model. Laryngoscope, 110(11), 1936-1942.

[16] Robey, T.C., Valimaa, T., Murphy, H.S., Tormala, P., Mooney, D.J. and Weatherly, R.A. (2000) Use of internal bioabsorbable PLGA "finger-type" stents in a rabbit tracheal reconstruction model. Archives of Otolaryngology-Head \& Neck Surgery, 126(8), 985-991.

[17] Hallers, E.J., Rakhorst, G., Marres, H.A., Jansen, J.A., Kooten, T.G., Schutte, H.K., Loon, J.P., Houwen, E.B. and Verkerke, G.J. (2004) Animal models for tracheal research. Biomaterials, 25(9), 1533-1543.

[18] Buhler, R.B., Sennes, L.U., Mauad, T., Melo, E.C., Silva, L.F. and Saldiva, P.H. (2008) Collagen fiber and versican distribution within the lamina propria of fetal vocal folds. Laryngoscope, 118(2), 371-374.

[19] Butler, J.E., Hammond, T.H. and Gray, S.D. (2001) Gender-related differences of hyaluronic acid distribution in the human vocal fold. Laryngoscope, 111(5), 907-911.

[20] Hammond, T.H., Gray, S.D. and Butler, J.E. (2000) Ageand gender-related collagen distribution in human vocal folds. The Annals of Otology, Rhinology, and Laryngology, 109(10 Pt 1), 913-920.

[21] Gray, S.D., Titze, I.R., Alipour, F. and Hammond, T.H. (2000) Biomechanical and histologic observations of vocal fold fibrous proteins. The Annals of Otology, Rhinology, and Laryngology, 109(1), 77-85.

[22] Gray, S.D., Titze, I.R., Chan, R. and Hammond, T.H, (1999) Vocal fold proteoglycans and their influence on biomechanics. Laryngoscope, 109(6), 845-854.

[23] Hammond, T.H., Zhou, R., Hammond, E.H., Pawlak, A. and Gray, S.D. (1997) The intermediate layer: A morphologic study of the elastin and hyaluronic acid constituents of normal human vocal folds. Journal of Voice, 11(1), 59-66.

[24] Pawlak, A.S., Hammond, T., Hammond, E. and Gray, S.D. (1996) Immunocytochemical study of proteoglycans in vocal folds. The Annals of Otology, Rhinology, and Laryngology, 105(1), 6-11.

[25] Chan, R.W., Fu, M., Young, L. and Tirunagari, N. (2007) Relative contributions of collagen and elastin to elasticity of the vocal fold under tension. Annals of Biomedical Engineering, 35(8), 1471-1483.

[26] Melo, E.C., Lemos, M., Aragao, X.F.J., Sennes, L.U., Nascimento, S.P.H. and Tsuji, D.H. (2003) Distribution of collagen in the lamina propria of the human vocal fold. Laryngoscope, 113(12), 2187-2191.

[27] Sivasankar, M. and Ivanisevic, A. (2007) Atomic force microscopy investigation of vocal fold collagen. Laryngoscope, 117(10), 1876-1881.

[28] Tateya, T., Tateya, I. and Bless, D.M. (2006) Collagen subtypes in human vocal folds. The Annals of Otology, Rhinology, and Laryngology, 115(6), 469-476.

[29] Tateya, T., Tateya, I. and Bless, D.M. (2007) Immuno-scanning electron microscopy of collagen types I and III in human vocal fold lamina propria. The Annals of Otology, Rhinology, and Laryngology, 116(2), 156-159.

[30] Sakae, F.A., Imamura, R., Sennes, L.U., Mauad, T., Sal- diva, P.H. and Tsuji, D.H. (2008) Disarrangement of collagen fibers in Reinke's edema. Laryngoscope, 118(8), 1500-1503.

[31] Sato, K., Hirano, M. and Nakashima, T. (2003) 3D structure of the macula flava in the human vocal fold. Acta Otolaryngologica, 123(2), 269-273.

[32] Sato, K., Hirano, M. and Nakashima, T. (2002) Agerelated changes of collagenous fibers in the human voca fold mucosa. The Annals of Otology, Rhinology, and Laryngology, 111(1), 15-20.

[33] Sato, K. and Hirano, M. (1995) Histologic investigation of the macula flava of the human vocal fold. The Annals of Otology, Rhinology, and Laryngology, 104(2), 138-143.

[34] Hirano, S., Minamiguchi, S., Yamashita, M., Ohno, T., Kanemaru, S.I. and Kitamura, M. (2008) Histologic characterization of human scarred vocal folds. Journal of Voice, 23(4), 399-407, Epub.

[35] Ximenes, F.J.A, Tsuji, D.H., Nascimento, P.H. and Sennes, L.U. (2003) Histologic changes in human vocal folds correlated with aging: A histomorphometric study. The Annals of Otology, Rhinology, and Laryngology, 112 (10), 894-898.

[36] Kamel, K.S., Beckert, L.E. and Stringer, M.D. (2009) Novel insights into the elastic and muscular components of the human trachea. Clinical Anatomy, 22(6), 689-697.

[37] Al-Zghoul, M.F., Ismail, Z.B., Al-Rukibat, R.K. and AlMajali, A.M. (2006) A quantitative study on the trachea of young Arabian camels (Camelus dromedarius). Journal of Camel Practice and Research, 13(2), 129-133.

[38] Cozzi, B., Bagnoli, P., Acocella, F. and Costantino, M.L. (2005) Structure and biomechanical properties of the trachea of the striped dolphin Stenella coeruleoalba: Evidence for evolutionary adaptations to diving. The Anatomical Record. Part A, Discoveries in Molecular, Cellular, and Evolutionary Biology, 284(1), 500-510.

[39] Pierson, D.J. (2009) The physiology of dinosaurs: Circulatory and respiratory function in the largest animals ever to walk the earth. Respiratory Care, 54(7), 887-911.

[40] Evans, M.J., Fanucchi, M.V., Baker, G.L., Winkle, L.S., Pantle, L.M., Nishio, S.J., Schelegle, E.S., Gershwin, L.J., Miller, L.A., Hyde, D.M. and Plopper, C.G. (2004) The remodelled tracheal basement membrane zone of infant rhesus monkeys after 6 months of recovery. Clinical and Experimental Allergy: Journal of the British Society for Allergy and Clinical Immunology, 34(7), 1131-1136.

[41] Evans, M.J., Winkle, L.S., Fanucchi, M.V., Toskala, E., Luck, E.C., Sannes, P.L. and Plopper, C.G. (2000) Three-dimensional organization of the lamina reticularis in the rat tracheal basement membrane zone. American Journal of Respiratory Cell and Molecular Biology, 22 (4), 393-397.

[42] Evans, M.J., Fanucchi, M.V., Baker, G.L., Winkle, L.S., Pantle, L.M., Nishio, S.J., Schelegle, E.S., Gershwin, L.J., Miller, L.A., Hyde, D.M., Sannes, P.L. and Plopper, C.G. (2003) Atypical development of the tracheal basement membrane zone of infant rhesus monkeys exposed to ozone and allergen. American Journal of Physiology. Lung Cellular and Molecular Physiology, 285(4), L931-L939.

[43] Amiri, M.H. and Gabella, G. (1988) Structure of the guinea-pig trachea at rest and in contraction. Anatomy and Embryology, 178(5), 389-397.

[44] Maki, J.M., Sormunen, R., Lippo, S., Kaarteenaho, W.R, 
Soininen, R. and Myllyharju, J. (2005) Lysyl oxidase is essential for normal development and function of the respiratory system and for the integrity of elastic and collagen fibers in various tissues. The American Journal of Pathology, 167(4), 927-936.

[45] Sasano, Y., Takahashi, I., Zhu, J.X., Ohtani, H., Mizoguchi, I. and Kagayama, M. (2001) Gene and protein expressions of type I collagen are regulated tissue-specifically in rat hyaline cartilages in vivo. European Journal of Morphology, 39(3), 149-154.

[46] Sasano, Y., Takahashi, I., Mizoguchi, I., Kagayama, M., Takita, H. and Kuboki, Y. (1998) Type X collagen is not localized in hypertrophic or calcified cartilage in the developing rat trachea. Anatomy and Embryology, 197(5), 399-403.

[47] Sasano, Y., Mizoguchi, I., Furusawa, M., Aiba, N., Ohtani, E., Iwamatsu, Y. and Kagayama, M. (1993) The process of calcification during development of the rat tracheal cartilage characterized by distribution of alkaline phosphatase activity and immunolocalization of types I and II collagens and glycosaminoglycans of proteoglycans. Anatomy and Embryology, 188(1), 31-39.

[48] Tamechika, I., Itakura, M., Saruta, Y., Furukawa, M., Kato, A., Tachibana, S. and Hirose, S. (1996) Accelerated evolution in inhibitor domains of porcine elafin family members. The Journal of Biological Chemistry, 271(12), $7012-7018$.

[49] Suzuki, Y., Furukawa, M., Abe, J., Kashiwagi, M. and Hirose, S. (2000) Localization of porcine trappin-2 (SKALP/elafin) in trachea and large intestine by in situ hybridization and immunohistochemistry. Histochemistry and Cell Biology, 114(1), 15-20.

[50] Kusafuka, K., Yamaguchi, A., Kayano, T. and Takemura, T. (2001) Ossification of tracheal cartilage in aged humans: A histological and immunohistochemical analysis. Journal of Bone and Mineral Metabolism, 19(3), 168-174.

[51] Roberts, C.R., Rains, J.K., Pare, P.D., Walker, D.C., Wiggs, B. and Bert, J.L. (1998) Ultrastructure and tensile properties of human tracheal cartilage. Journal of Biomechanics, 31(1), 81-86.

[52] Rao, R.A., Mehta, M.R. and Toussaint, K.C. (2009) Fourier transform-second-harmonic generation imaging of biological tissues. Optics Express, 17(17), 14534-14542.

[53] Maki, K., Hayashi, S., Nishioka, T., Kimura, M. and Noguch, T. (2000) A new type of matrix vesicles is found in fetal bovine tracheal cartilage. Connect Tissue Research, 41(2), 109-115.

[54] Detamore, M.S. and Athanasiou, K.A. (2003) Structure and function of the temporomandibular joint disc: implications for tissue engineering. Journal of Oral and Max- illofacial Surgery, 61(4), 494-506.

[55] Poole, A.R., Webber, C., Pidoux, I., Choi, H. and Rosenberg, L.C. (1986) Localization of a dermatan sulfate proteoglycan (DS-PGII) in cartilage and the presence of an immunologically related species in other tissues. The Journal of Histochemistry and Cytochemistry: Official Journal of the Histochemistry Society, 34(5), 619-625.

[56] Danielson, K.G., Baribault, H., Holmes, D.F., Graham, H., Kadler, K.E. and Iozzo, R.V. (1997) Targeted disruption of decorin leads to abnormal collagen fibril morphology and skin fragility. Journal of Cell Biology, 136, 729-743.

[57] Teng, Z., Ochoa, I., Li, Z., Lin, Y., Rodriguez, J.F., Bea, J.A. and Doblare, M. (2008) Nonlinear mechanical property of tracheal cartilage: A theoretical and experimental study. Journal of Biomechanics, 41(9), 1995-2002.

[58] Miller, T.L., Altman, A.R., Tsuda, T. and Shaffer, T.H. (2007) An ultrasound imaging method for in vivo tracheal bulk and Young's moduli of elasticity. Journal of Biomechanics, 40(7), 1615-1621.

[59] Rains, J.K., Bert, J.L., Roberts, C.R. and Pare, P.D. (1992) Mechanical properties of human tracheal cartilage. Journal of Applied Physiology, 72(1), 219-225.

[60] Jayaraju, S.T., Paiva, M., Brouns, M., Lacor, C. and Verbanck, S. (2008) Contribution of upper airway geometry to convective mixing. Journal of Applied Physiology, 105(6), 1733-1740.

[61] Russo, J., Robinson, R. and Oldham, M.J. (2008) Effects of cartilage rings on airflow and particle deposition in the trachea and main bronchi. Medical Engineering \& Physics, 30(5), 581-589.

[62] Rakesh, V., Rakesh, N.G,. Datta, A.K., Cheetham, J. and Pease, A.P. (2008) Development of equine upper airway fluid mechanics model for Thoroughbred racehorses. Equine Veterinary Journal, 40(3), 272-279.

[63] Nazridoust, K. and Asgharian, B. (2008) Unsteady-state airflow and particle deposition in a three-generation human lung geometry. Inhalation Toxicology, 20(6), 595610.

[64] Isaacs, K.K., Schlesinger, R.B. and Martonen, T.B. (2006) Three-dimensional computational fluid dynamics simulations of particle deposition in the tracheobronchial tree. Journal of Aerosol Medicine, 19(3), 344-352.

[65] Martonen, T.B., Zhang, Z., Yu, G. and Musante, C.J. (2001) Three-dimensional computer modeling of the human upper respiratory tract. Cell Biochemistry and Biophysics, 35(3), 255-261.

[66] Delaere, P., Vranckx, J., Verleden, G., Leyn, P. and Raemdonck, D. (2010) Tracheal allotransplantation after withdrawal of immunosuppressive therapy. The New England Journal of Medicine, 362(2), 138-145. 